\title{
Analisis Kepuasan Pelanggan dalam Membeli Buah-buahan Segar di Moena Fresh Bali
}

\author{
PUTU OKA WARDIKA, RATNA KOMALA DEWI, \\ NI WAYAN PUTU ARTINI \\ Program Studi Agribisnis Fakultas Pertanian Universitas Udayana \\ Jl. PB. Sudirman Denpasar 80232 \\ Email: okawardika@gmail.com \\ ratnadewi61@ymail.com
}

\begin{abstract}
Analysis Customer Satisfaction in Buying Fresh Fruits in Moena Fresh Bali

Increased consumption of fruits in the country have an impact on the growth of fruit sales in Indonesia. This increase causes the appearance of stiff competition in the business of fruits. Moena Fresh Bali as one of the companies that sell fresh fruits must innovate or improve the shortage so that the consumers do not turn to other products. Consumer behavior may help explain how consumers obtain satisfaction. The purpose of this research is to determine satisfaction of Moena Fresh Bali consumers and to find out actions to increase customer satisfaction of Moena Fresh. The location of the research was conducted at four Moena Fresh outlets as it was considered to represent consumers in every sub-district in Denpasar City. The number of respondents was as many as 50 respondents and the sampling was conducted by using accidental sampling. Types of data collected include quantitative and qualitative data which were sourced from primary and secondary data. Methods of data collection were by using interview techniques, observation, and documentation. Data analysis methods used were descriptive analysis, Importance Performance Analysis and Customer Satisfaction Index. Based on the results of research, the calculation of CSI to the attributes of Moena Fresh Bali was 77.6\% i.e. it meets the criteria of satisfaction. Based on the Matrix of Importance Performance, product attributes are classified into four quadrants and actions to improve customer satisfaction are through the improvement of attributes that become the main priority, namely the attributes of advertising / promotion, price, and discounts. The study suggests that Moena Fresh Bali should perform printed and electronic publications and set competitive prices to maintain its customers.
\end{abstract}

Keywords: fresh fruits, moena fresh bali, customer satisfaction, importance performance analysis

\section{Pendahuluan}

\subsection{Latar Belakang}

Salah satu subsektor pertanian yang memegang peranan penting adalah subsector hortikultura. Buah-buahan merupakan salah satu komoditas hortikultura yang mempunyai nilai ekonomis tinggi dan memegang peranan penting bagi pembangunan pertanian (Widiyanto, 2016). 
Berkembangnya komoditas buah-buahan di Indonesia hingga saat ini dapat dilihat dari konsumsi buah-buahan per kapita yang meningkat setiap tahunnya. Sebagai informasi pada tahun 2012, konsumsi buah-buahan per kapita sebanyak $17,520 \mathrm{~kg}$. Tahun 2013, konsumsi buah-buahan per kapita meningkat menjadi 21,111 kg. Jumlah konsumsi buah-buahan per kapita juga mengalami peningkatan pada tahun 2014 menjadi 24,513 kg. Peningkatan jumlah konsumsi buahan-buahan diperkirakan akan terus bertambah setiap tahunnya seiring bertambahnya jumlah penduduk. Hal ini dapat dilihat pada Tabel 1 mengenai seberapa banyak jenis buahbuahan yang telah dikonsumsi per kapita di Indonesia.

Tabel 1.

Konsumsi Buah-buahan per Kapita di Indonesia dari Tahun 2012-2014

\begin{tabular}{lcrrrrr}
\hline \multirow{2}{*}{ Jenis Buah } & \multicolumn{3}{c}{2012} & \multicolumn{2}{c}{2013} & \multicolumn{2}{c}{2014} \\
\cline { 2 - 7 } & $\begin{array}{c}\text { Kuantitas } \\
(\mathrm{Kg})\end{array}$ & $\begin{array}{c}\text { Persentase } \\
(\%)\end{array}$ & $\begin{array}{r}\text { Kuantitas } \\
(\mathrm{Kg})\end{array}$ & $\begin{array}{r}\text { Persentase } \\
(\%)\end{array}$ & $\begin{array}{r}\text { Kuantitas } \\
(\mathrm{Kg})\end{array}$ & $\begin{array}{r}\text { Persentase } \\
(\%)\end{array}$ \\
\hline Alpokat & 0,209 & 1,19 & 0,417 & 1,98 & 0,574 & 2,34 \\
Belimbing & 0,052 & 0,30 & 0,052 & 0,25 & 0,052 & 0,21 \\
Duku & 0,991 & 5,66 & 1,977 & 9,36 & 0,469 & 1,91 \\
Durian & 0,991 & 5,66 & 1,408 & 6,67 & 1,981 & 8,08 \\
Jeruk & 2,764 & 15,78 & 2,242 & 10,62 & 2,711 & 11,06 \\
Jambu & 0,365 & 2,08 & 0,417 & 1,98 & 0,365 & 1,49 \\
Mangga & 0,156 & 0,89 & 0,156 & 0,74 & 0,261 & 1,06 \\
Nanas & 0,156 & 0,89 & 0,209 & 0,99 & 0,215 & 0,88 \\
Nangka & 0,104 & 0,59 & 0,104 & 0,49 & 0,156 & 0,64 \\
Pepaya & 1,616 & 9,22 & 1,825 & 8,64 & 2,086 & 8,51 \\
Pisang Ambon & 1,825 & 10,42 & 1,251 & 5,93 & 1,408 & 5,74 \\
Pisang Raja & 0,834 & 4,76 & 0,834 & 3,95 & 0,886 & 3,61 \\
Pisang Lainnya & 3,129 & 17,86 & 3,546 & 16,80 & 3,911 & 15,95 \\
Rambutan & 2,190 & 12,50 & 4,119 & 19,51 & 6,987 & 28,50 \\
Salak & 1,095 & 6,25 & 1,199 & 5,68 & 1,043 & 4,25 \\
Sawo & 0,104 & 0,59 & 0,104 & 0,49 & 0,104 & 0,42 \\
Semangka & 0,939 & 5,36 & 1,251 & 5,93 & 1,304 & 5,32 \\
\hline Total Konsumsi & 17,520 & 100 & 21,111 & 100 & 24,513 & 100 \\
\hline Sumber : Pusat Data dan Sistem Informasi Pertanian, 2015 & & &
\end{tabular}

Sumber : Pusat Data dan Sistem Informasi Pertanian, 2015

Adanya peningkatan jumlah penduduk sejalan dengan pendapatan dan kualitas pendidikan, meningkat pula kesadaran masyarakat akan kebutuhan komposisi gizi yang seimbang merupakan peluang bagi pasar buah-buahan (Patiroi, 2008). Munculnya berbagai fasilitas perbelanjaan merupakan salah satu bentuk perkembangan untuk memenuhi keinginan dan kebutuhan masyarakat akan buahbuahan segar. Perubahan tersebut dapat dilihat dari kehadiran pasar modern yang menjual buah-buahan segar perlahan mulai menggeser posisi pasar tradisional yang selama ini menjadi sentra penjualan buah-buahan segar. 
Salah satu bentuk perkembangan pasar modern adalah bisnis retail modern buah-buahan. Retail modern hadir dengan konsep one stop shopping dan menawarkan banyak kelebihan dibandingkan dengan ritel tradisional, seperti harga pasti, suasana nyaman, lingkungan bersih, relatif aman dari tindakan kriminalitas, variasi produk lengkap, kualitas produk terjamin, pelayanan yang baik, kemudahan dalam bertransaksi, serta program promosi yang gencar dilakukan oleh peritel melalui media elektronik maupun media cetak (Hidayati, 2010).

CV. Moena Abadi Sejahtera atau dikenal juga dengan Moena Fresh Bali adalah salah satu perusahaan ritel yang menyediakan buah-buahan segar sebagai produk utamanya. Moena Fresh Bali sudah berdiri kurang lebih 24 tahun sejak dibentuknya cabang usaha Bali pada tahun 1992. Saat ini Moena Fresh Bali telah memiliki sembilan outlet yang tersebar di Kota Denpasar dan Kabupaten Badung.

Menghadapi perkembangan pasar yang semakin pesat, setiap perusahaan harus mampu bersaing secara global. Salah satu cara untuk memenangkan persaingan, perusahaan harus mampu memberikan kepuasan kepada para pelanggannya, misalnya dengan memberikan produk yang mutunya lebih baik, harganya lebih murah, penyerahan produk yang lebih cepat dan pelayanan yang lebih baik dari pesaingnya (Supranto, 2001).

Berdasarkan hal tersebut, Moena Fresh Bali perlu melakukan suatu upaya agar konsumen tetap loyal dengan cara mengidentifikasi segala hal yang berkaitan dengan kepuasan konsumen baik terhadap buah-buahan yang diperjualbelikan maupun pelayanan Moena Fresh Bali.

\subsection{Tujuan Penelitian}

Penelitian ini bertujuan untuk mengetahui kepuasan konsumen terhadap buahbuahan segar yang diperjualbelikan di Moena Fresh bali, untuk mengetahui kaitan atribut penjualan buah-buahan segar terhadap kepuasan pelanggan Moena Fresh Bali serta untuk mengetahui tindakan yang harus dilakukan untuk meningkatkan kepuasan konsumen Moena Fresh Bali.

\section{Metodologi Penelitian}

\subsection{Lokasi dan Waktu Penelitian}

Metode penentuan tempat penelitian diambil secara sengaja atau purposive yaitu pengambilan obyek dengan sengaja didasarkan atas ke empat outlet dianggap mewakili konsumen yang berada di tiap kecamatan di Kota Denpasar. Tempat penelitian dilakukan di empat outlet Moena Fresh Bali yang tersebar di Kota Denpasar yaitu outlet Diponegoro, outlet Kesiman, outlet Panjer, dan outlet Tohpati. Penelitian dimulai dari bulan Februari 2017 sampai bulan Maret 2017. 


\subsection{Populasi dan Sampel Penelitian}

Populasi dalam penelitian ini yaitu dari seluruh konsumen Moena Fresh Bali di Kota Denpasar. Jumlah populasi penelitian ini tidak diketahui secara jelas. Jumlah sampel atau responden yang terlibat dalam penelitian ini adalah individu yang melakukan transaksi di Moena Fresh Bali dengan frekuensi belanja $\geq 2$ kali dalam satu bulan yang berjumlah 50 orang responden. Ukuran responden tersebut didasarkan pada teori limit pusat yang menyatakan bahwa bila $\mathrm{n}$ besar (secara empiris $\geq 30$ ) distribusi peluang rata-rata akan mengikuti distribusi normal (Sugiarto, 2002). Teknik penarikan sampel atau responden yang digunakan dalam penelitian ini adalah dengan metode accidental sampling.

\subsection{Jenis dan Sumber Data}

Jenis data yang dikumpulkan dalam penelitian ini ada dua jenis yaitu data kuantitatif dan data kualitatif. Data kuantitatif yang digunakan berupa hasil wawancara dengan menggunakan kuesioner kepada responden. Data tersebut diukur menggunakan skala likert. Data kualitatif yang digunakan dalam penelitian ini mencakup gambaran umum tempat penelitian serta karakteristik responden.

Sumber data berasal dari data primer dan data sekunder. Data primer berasal dari hasil wawancara dengan memberikan daftar pertanyaan atau kuesioner yang akan dinilai oleh responden. Data sekunder yang digunakan berupa gambaran umum perusahaan dan struktur organisasi Moena Fresh Bali serta beberapa studi pustaka yang berhubungan.

\subsection{Metode Pengumpulan Data, Metode Pengukuran, dan Operasional Variabel}

Metode pengumpulan data yang digunakan dalam penelitian ini yaitu wawancara, observasi, dan dokumentasi. Metode pengukuran yang dipakai dalam penelitian ini adalah skala likert yaitu skala yang digunakan untuk mengukur sikap, pendapat dan persepsi seseorang atau sekelompok orang tentang fenomena sosial (Sugiyono, 2009). Variabel dalam penelitian ini mencakup tingkat kepentingan (importance) dan tingkat kinerja (performance) menurut penilaian responden.

\subsection{Metode Analisis Data}

Metode analisis data yang digunakan dalam penelitian ini adalah dengan analisis deskriptif yang digunakan untuk menggambarkan profil responden yang dikelompokkan berdasarkan jawaban yang sama, kemudian dipersentasekan berdasarkan jumlah responden. Metode selanjutnya adalah adalah Customer Satisfaction Index untuk menjawab tujuan pertama yaitu tingkat kepuasan konsumen dalam membeli buah-buahan di Moena Fresh dan metode yang terakhir yang digunakan adalah Importance Performance Analysis, metode ini digunakan untuk menjawab tujuan kedua yaitu untuk menunjukkan tindakan yang dapat dilakukan Moena Fresh Bali untuk meningkatkan kepuasan pelanggan. 


\section{Hasil dan Pembahasan}

\subsection{Karakteristik Konsumen}

Penelitian yang dilakukan terhadap konsumen Moena Fresh menghasilkan beberapa karakteristik demografi yakni meliputi umur/usia, jenis kelamin, pekerjaan, status pernikahan, pendidikan terakhir dan pendapatan per bulan.

\subsection{Karakteristik Demografi}

a. Karakteristik responden berdasarkan jenis kelamin diketahui mayoritas konsumen buah-buahan di Moena Fresh Bali adalah perempuan yang terdiri atas $64 \%$ dari jumlah responden. Banyaknya konsumen perempuan ini mengkondisikan bahwa perempuan adalah orang yang lebih dominan dalam menentukan keputusan dalam membeli buah-buahan segar di Moena Fresh Bali.

b. Karakteristik responden berdasarkan didominasi oleh konsumen kategori dewasa awal yaitu usia 26 - 35 tahun sebanyak 20 orang (40\%), diikuti dengan responden kategori dewasa akhir yang berumur $36-45$ tahun sebanyak 11 orang (22\%). Hal ini menandakan bahwa konsumen usia kategori dewasa awal adalah usia yang produktif sehingga kebutuhan akan seratnya yang tinggi dan memutuskan untuk membeli buah-buahan.

c. Karakteristik responden berdasarkan status pernikahan didominasi oleh responden menikah dengan jumlah 32 orang (64\%) dan belum menikah sebanyak 18 orang (36\%). Hal ini menunjukkan bahwa konsumen Moena Fresh yang sudah menikah akan lebih banyak melakukan pembelian buah-buahan untuk kebutuhan keluarganya.

d. Karakteristik responden berdasarkan pendidikan, gambaran yang diperoleh adalah umumnya tingkat pendidikan responden cukup bervariasi mulai dari tingkat SD sampai pasca sarjana, responden yang terbanyak adalah tingkat SMA sebanyak 24 orang (48\%) kemudian tingkat sarjana dengan jumlah 15 orang (30\%). Hal ini menunjukkan bahwa konsumen yang berbelanja di Moena Fresh Bali adalah mereka yang mempunyai tingkat pendidikan relatif tinggi.

e. Berdasarkan karakteristik pekerjaan, mayoritas pekerjaan responden yang terbesar adalah pegawai negeri sebanyak 19 orang (38\%). Hal ini terjadi karena lokasi Moena Fresh berada pada jalur pertokoan yang akan sering dilalui oleh karyawan swasta ketika berangkat dan pulang kerja. Kesimpulannya adalah jumlah konsumen dari kalangan karyawan swasta lebih mendominasi dibandingkan dengan profesi lain.

f. Berdasarkan karakteristik pendapatan responden terbesar dalam penelitian ini adalah responden yang berpenghasilan perbulannya $>\mathrm{Rp} 2.500 .000-\mathrm{Rp}$ 5.000.000 sebanyak 17 orang (34\%), diikuti oleh responden berpenghasilan perbulan >Rp $1.000 .000-2.500 .000$ sebanyak 12 orang (24\%). Hal ini menunjukkan bahwa konsumen yang berbelanja di Moena Fresh pada umumnya berasal dari golongan ekonomi menengah ke atas. 


\subsection{Penilaian Responden}

a. Berdasarkan penilaian tingkat kepentingan atribut kebersihan toko memperoleh skor kepentingan tertinggi, diikuti oleh atribut kualitas buah baik dan variasi jenis buah. Responden menganggap bahwa ketiga atribut teratas ini penting. Hasil penilaian tingkat kepentingan atribut Moena Fresh Bali ini dapat disimpulkan bahwa atribut yang sangat diperhatikan oleh konsumen adalah atribut kebersihan toko, kualitas buah baik, dan variasi jenis buah, sedangkan untuk atribut lainnya tidak terlalu diperhatikan oleh konsumen.

b. Berdasarkan penilaian tingkat kinerja responden masih merasa kurang puas dengan bebrapa atribut yaitu potongan harga karena konsumen belum pernah merasakan potongan harga dari Moena Fresh sebelumnya dan atribut musik karena konsumen merasa musik yang diputar tidak terdengar atau tidak dihidupkan. Atribut dengan total skor kepuasan tertinggi adalah atribut kualitas jenis buah karena buah-buahan yang dijual oleh Moena Fresh Bali memiliki kualitas yang baik dan dijaga kualitasnya di setiap outlet sesuai standar yang berlaku di perusahaan.

\subsection{Customer Satisfaction Index}

Berdasarkan hasil perhitungan CSI Moena Fresh (Tabel 2), nilai indeks kepuasan pelanggan Moena Fresh Bali secara keseluruhan sebesar 77,6 \%. Nilai tersebut berada pada rentang $61 \%$ - 80\% dengan begitu indeks kepuasan keseluruhan konsumen yang dihitung berdasarkan atribut produk termasuk pada kriteria puas. Namun sebaiknya perusahaan Moena Fresh Bali tetap perlu meningkatkan kinerja agar kriteria indeks kepuasan pelanggan Moena Fresh Bali meningkat menjadi sangat puas yakni mencapai $100 \%$ sehingga pelanggan akan merasa sangat puas terhadap kinerja Moena Fresh Bali dan mendapatkan pelanggan tetap yang tidak beralih ke pesaing lainnya.

Berdasarkan Tabel 2, nilai indeks kepuasan pelanggan Moena Fresh Bali secara keseluruhan sebesar 77,6 \% ini berarti terdapat selisih sebesar 22,4\% untuk mencapai kepuasan pelanggan sebesar $100 \%$. Selisih tersebut diakibatkan oleh beberapa atribut yang nilai tingkat kepentingan dan tingkat kinerjanya dibawah ratarata. Hal tersebut berakibat pada nilai weighted score (WS) yang digunakan untuk mengukur nilai indeks kepuasan pelanggan secara keseluruhan menjadi belum maksimal. Atribut-atribut yang menyebabkan selisih adalah tempat parkir, fasilitas pembayaran, fasilitas pesan antar, musik, aroma ruangan, temperatur ruangan, iklan/promosi, harga, dan potongan harga. Atribut-atribut tersebut perlu mendapat perhatian khusus untuk meningkatkan kepuasan pelanggan 
Tabel 2.

Perhitungan Customer Satisfaction Indeks (CSI) Moena Fresh Bali

\begin{tabular}{|c|c|c|c|c|c|}
\hline NO & ATRIBUT & RSP & WF & RSK & WS \\
\hline 1. & Lokasi & 4,36 & 0,048 & 4,12 & 0,199 \\
\hline 2. & Tempat Parkir & 4,22 & 0,047 & 3,64 & 0,170 \\
\hline 3. & Kesopanan dan keramahan & 4,42 & 0,049 & 3,96 & 0,194 \\
\hline 4. & Penampilan pramuniaga & 4,40 & 0,049 & 3,96 & 0,193 \\
\hline 5. & Kecepatan transaksi & 4,28 & 0,047 & 4,02 & 0,191 \\
\hline 6. & Fasilitas Pembayaran & 3,74 & 0,041 & 3,70 & 0,153 \\
\hline 7. & Fasilitas Pesan antar & 3,84 & 0,043 & 3,74 & 0,159 \\
\hline 8. & Fasilitas Pembungkusan parsel & 4,20 & 0,047 & 4,06 & 0,189 \\
\hline 9. & Tata ruang dan dekorasi toko & 4,28 & 0,047 & 4,02 & 0,191 \\
\hline 10. & Tata letak produk & 4,30 & 0,048 & 4,16 & 0,198 \\
\hline 11. & Musik & 3,50 & 0,039 & 3,38 & 0,131 \\
\hline 12. & Kebersihan & 4,78 & 0,053 & 4,12 & 0,218 \\
\hline 13. & Aroma ruangan & 4,10 & 0,045 & 3,84 & 0,174 \\
\hline 14. & Temperatur ruangan & 4,04 & 0,045 & 3,90 & 0,174 \\
\hline 15. & Iklan dan promosi & 4,54 & 0,050 & 3,20 & 0,161 \\
\hline 16. & Variasi jenis buah & 4,64 & 0,051 & 4,22 & 0,217 \\
\hline 17. & Kualitas buah baik & 4,70 & 0,052 & 4,44 & 0,231 \\
\hline 18. & Ketersediaan buah mutu baik & 4,54 & 0,050 & 4,22 & 0,212 \\
\hline 19. & Harga & 4,50 & 0,050 & 3,56 & 0,177 \\
\hline 20. & Potongan harga & 4,50 & 0,050 & 2,96 & 0,148 \\
\hline 21. & Pelayanan sesudah transaksi & 4,42 & 0,049 & 4,16 & 0,204 \\
\hline & Total & 90,30 & 1,000 & 81,38 & 3,880 \\
\hline \multicolumn{5}{|c|}{$\mathrm{CSI}=(\mathrm{WS}: 5) \times 100 \%$} & $77,6 \%$ \\
\hline
\end{tabular}

Sumber : Data Primer 2017

Keterangan :

RSP : Rara-rata skor kepentingan

WF : Weighting Factor $[\mathrm{WF}=(\mathrm{RSP} / 90,30)]$

RSK : Rata-rata skor kinerja

WS : Weighted Score [WS=(RSK X WF)]

\subsection{Importance Performance Analysis (IPA)}

Hasil analisis model IPA ini berupa dimensi-dimensi atribut yang mempengaruhi strategi peningkatan kepuasan konsumennya. Data penilaian tingkat kepentingan dan tingkat kinerja kemudian dimasukkan ke dalam kuadran yang terbagi menjadi empat dengan bantuan aplikasi SPSS.

Kuadran I menunjukkan atribut-atribut yang dianggap penting bagi pelanggan yang ternyata belum sesuai dengan keinginan pelanggan. Atibut-atribut yang terdapat pada kuadran I adalah atribut iklan/promosi, harga, dan potongan harga. Jadi, atribut tersebut perlu mendapat perhatian khusus.

Kuadran II menunjukkan faktor-faktor atau atribut yang dirasakan penting oleh pelanggan dan sudah sesuai dengan apa yang dirasakan oleh pelanggan. Atributatribut yang berada pada kuadran ini adalah lokasi, kesopanan dan keramahan pramuniaga, penampilan pramuniaga, tata letak produk, kebersihan, variasi jenis buah, kualitas buah, ketersediaan buah dengan mutu baik, dan pelayanan sesudah 
transaksi. Jadi atribut-atribut tersebut harus dipertahankan oleh pengelola Moena Fresh Bali.

Kuadran III menunjukkan unsur-unsur yang dianggap kurang penting oleh konsumen dalam membeli buah-buahan segar tetapi kinerjanya kurang begitu istimewa. Atribut yang berada dalam kuadran ini adalah musik, tempat parkir, fasilitas pembayaran, fasilitas pesan antar, dan aroma ruangan. Hal tersebut menandakan bahwa atribut-atribut tersebut menjadi prioritas kedua dalam pengelolaan manajemen Moena Fresh Bali.

Kuadran IV menunjukkan bahwa atribut yang dianggap kurang penting ternyata telah dijalankan dengan sangat baik oleh pihak perusahaan, dalam hal ini dianggap berlebihan. Atribut buah-buahan segar di Moena Fresh yang terdapat dalam kuadran ini adalah tata ruang dan dekorasi toko, kecepatan transaksi, pembungkusan parsel, dan temperatur ruangan. Hasil dari diagram kartesius dapat dilihat pada Gambar 1.

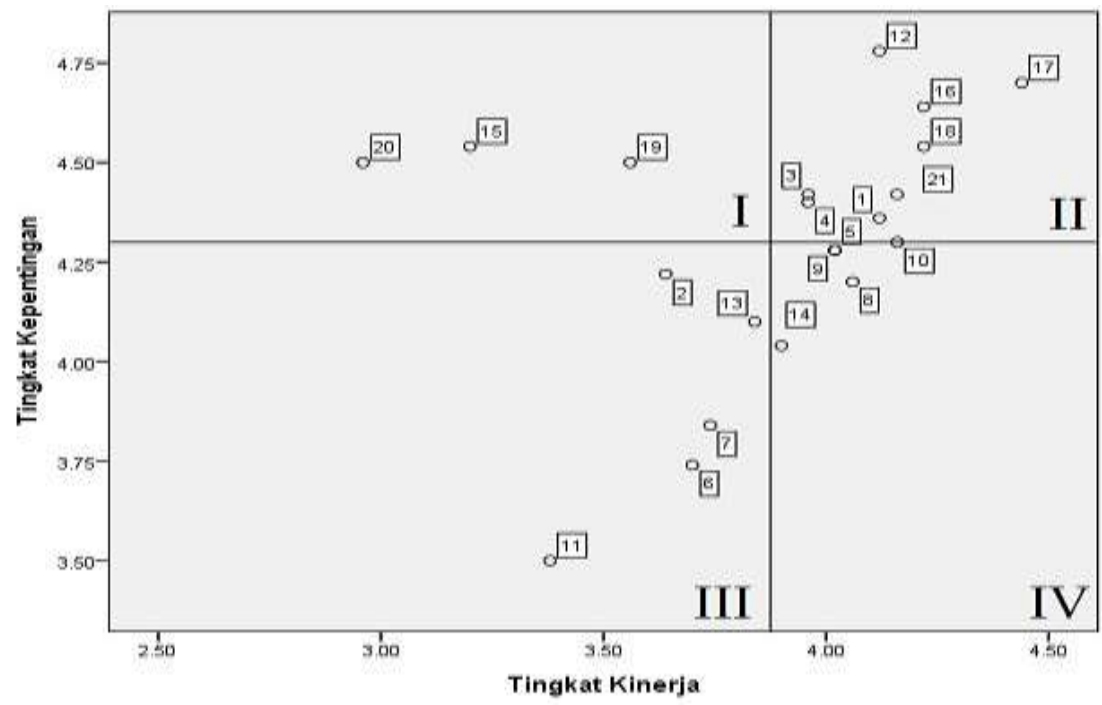

Gambar 1.

Matriks Importance Performance Analysis

Keterangan :

1 = Lokasi

2 = Tempat Parkir

$12=$ Kebersihan outlet

3 = Keramahan dan Kesopanan Pramuniaga

$13=$ Aroma ruangan outlet

4 = Penampilan pramuniaga

$14=$ Temperatur ruangan outlet

$5=$ Kecepatan transaksi

$15=$ Iklan/promosi

6 = Fasilitas pembayaran credit/debit card

$16=$ Variasi jenis buah

$7=$ Fasilitas pesan antar

$8=$ Fasilitas pembungkusan parcel

$17=$ Kualitas buah baik

$18=$ Ketersediaan buah mutu baik

9 = Lay out/tata ruang dan dekorasi outlet

$19=$ Harga

$10=$ Display produk dan tata letak produk

$20=$ Potongan harga

$11=$ Musik/Suara

$21=$ Pelayanan setelah transaksi 


\section{Simpulan}

\subsection{Simpulan}

Berdasarkan hasil dan pembahasan tersebut maka peneliti dapat menyimpulkan sebagai berikut:

1. Kepuasan konsumen terhadap buah-buahan yang diperjualbelikan di Moena Fresh Bali dapat dilihat dari perhitungan CSI (Customer Satisfaction Index) atau tingkat kepuasan konsumen terhadap atribut Moena Fresh Bali yaitu dengan indeks kepuasan sebesar 77,6\% yakni memenuhi kriteria puas. Selisih kepuasan sebanyak $22,4 \%$ diakibatkan oleh atribut yang memiliki penilaian dibawah ratarata.

2. Berdasarkan pengolahan data dengan menggunakan metode Importance Performance Analysis (IPA) menghasilkan atribut-atribut yang tersebar pada empat kuadran. Atribut-atribut yang dianggap penting bagi pelanggan ternyata belum sesuai dengan keinginan pelanggan adalah : iklan/promosi, harga, dan potongan harga. Atribut-atribut tersebut perlu mendapat perhatian khusus bagi perusahaan sebagai tindakan untuk meningkatkan kepuasan pelanggan Moena Fresh Bali.

\subsection{Saran}

Adapun beberapa saran yang penulis dapat berikan berdasarkan hasil penelitian adalah sebagai berikut.

1. Perusahaan perlu memperbaiki atribut-atribut yang menjadi prioritas pada kuadran I yaitu iklan/promosi, harga, dan potongan harga. Keberadaan buahbuahan segar di Moena Fresh perlu dipublikasikan di media cetak lokal serta pembuatan banner di setiap outletnya yang diletakkan di depan area outlet berisikan jenis buah yang sedang mendapat potongan harga. Penetapan harga dan potongan harga diharapkan sama dengan pesaing atau lebih rendah dari pesaing, agar dapat merebut konsumen dari para pesaing.

2. Perusahaan dapat memperbaiki atribut pada kuadran III yaitu musik, tempat parkir, fasilitas pembayaran, fasilitas pesan antar, dan aroma ruangan yang menjadi prioritas kedua dan mengurangi kinerja pada atribut yang berada pada kuadran IV yaitu tata ruang dan dekorasi toko, kecepatan transaksi, pembungkusan parsel, dan temperatur ruangan agar kinerja perusahaan dapat lebih efisien dalam pengalokasian sumber daya yang ada.

3. Kepada peneliti selanjutnya agar dapat menganalisis kepuasan konsumen Moena Fresh Bali di seluruh outlet yang ada serta menganalisis loyalitas konsumen.

\section{Ucapan Terima Kasih}

Penulis mengucapkan banyak terimakasih kepada semua pihak yang telah membantu dalam pelaksanaan penelitian ini hingga termuat di e-jurnal. 


\section{Daftar Pustaka}

Kementrian Pertanian. 2015. Statistik Konsumsi Pangan 2015. www.pertanian.go.id Diakses pada tanggal 16 November 2016

Hidayati, Nurul. 2010. Hubungan Retail Mix dengan Preferensi Konsumen Pada Tempat Berbelanja Barang Kebutuhan Rumah Tangga di Pasar Tradisional dan Pasar Modern (Berdasarkan Persepsi Konsumen di Kota Bandung). Skripsi pada Universitas Widyatama Bandung. Jawa Barat.

Kotler, Philip dan Amstrong. 2008. Manajemen Pemasaran. Edisi Bahasa Indonesia. PT. INDEKS : Jakarta

Lalala, Eden Poster. 2016. Analisis Kepuasan Konsumen Pada Produk Waralaba The Cap Poci di Kecamatan Denpasar Selatan Kota Denpasar. Skripsi pada Universitas Udayana. Bali

Supranto. 2001. Pengukuran Tingkat Kepuasan Pelanggan. Penerbit PT. Rineka Cipta : Jakarta

Sugiyono. 2009. Metode Penelitian Bisnis. Alfabeta, Bandung

Umar, H. 2005. Riset Pemasaran dan Perilaku Konsumen. PT. Gramedia Pustaka Utama dengan Jakarta Business Research Centre. Jakarta

Utami, Christina W. 2008. Manajemen Ritel-Strategi dan Implementasi Ritel Modern. Penerbit Salemba Empat. Jakarta

Patiroi, Andi Ihwan. 2008. Analisis Kepuasan Konsumen Buah-Buahan Segar di Swalayan Surya Indah. Skripsi pada Fakultas Pertanian Institut Pertanian Bogor. Jawa Barat

Widiyanto, Nerisa Agnesia. 2016. Sikap, Preferensi, dan Keputusan Pembelian Konsumen Terhadap Buah Apel (Kasus: Kota Malang dan Kota Surabaya Provinsi Jawa Timur). Tesis pada Sekolah Pascasarjana Institut Pertanian Bogor. Jawa Barat. 